\title{
CBCT Findings in Cleidocranial Dysplasia
}

\author{
Dr. Akshay Agarwal ${ }^{*}$, Dr. Kriti Shrivastava ${ }^{2}$, Dr.Poorva Tiwari ${ }^{3}$, Dr. Prashant P Jaju ${ }^{4}$
}

${ }^{1}$ Post Graduate Student, Department of Oral Medicine and Radiology, Rishiraj College of Dental Sciences and Research Centre Bhopal, Madhya Pradesh, India

${ }^{2}$ Reader, PG guide Department of Oral Medicine and Radiology, Rishiraj College of Dental Sciences and Research Center, Bhopal, India

${ }^{3}$ Senior lecturer, Department of Oral Medicine and Radiology, Rishiraj College of Dental Sciences and Research Center, Bhopal, India

${ }^{4}$ Head of Department, Department of Oral Medicine and Radiology, Rishiraj College of Dental Sciences and Research Center, Bhopal, India

DOI: $10.36347 /$ sjds.2020.v07i01.004

| Received: 20.11.2019 | Accepted: 27.11.2019| Published: 30.01.2020

*Corresponding author: Dr. Akshay Agarwal

Abstract

Cleidocranial dysplasia (CCD) it is an autosomal dominant skeletal dysplasia caused by mutation in CBFA1 (Core Binding Factor Alpha), a member of runt family of transcription factors mapped to chromosome 6p21. Radiographic images are important tools for the diagnosis of CCD. On dental radiographs, it is possible to observe 2 features of the classical triad of CCD: multiple supernumerary teeth; and open sutures and fontanelles of the skull. Third important feature hypoplasia of clavicles need additional chest radiograph. Most of mid-facial features of this syndrome can be visualized on CBCT images which save patient from exposure to different views of 2 dimensional imaging required to see widespread involvement of skull but also help in treatment planning for missing permanent teeth including accurate study of the morphology, location, alignment, proximity of teeth to structures like inferior alveolar canal and maxillary sinus well as the quality and quantity of basal bone available which could help a great deal in orthodontic planning, surgical extraction and prosthetic rehabilitation. Considering its valuable importance, CBCT is advisable in all such syndromes with multiple impacted teeth for diagnosis and treatment planning.

Keywords: Cleidocranial Dysplasia, Cone Beam Computed Tomography, Clavicle.

Copyright @ 2020: This is an open-access article distributed under the terms of the Creative Commons Attribution license which permits unrestricted use, distribution, and reproduction in any medium for non-commercial use (NonCommercial, or CC-BY-NC) provided the original author and source are credited.

\section{INTRODUCTION}

Cleidocranial dysplasia (CCD) is an autosomal dominant inherent condition with characteristic skeletal clinico-radiological findings [1]. Most common dental manifestations associated with cleidocranial dysplasia are impacted permanent teeth, supernumerary teeth, over-retained deciduous teeth, crowding of arches due to same reasons [4-6]. Scheuthauer was probably the first to describe the syndrome accurately [2]. Marie and Sainton in 1898 coined the name "dysostose cléidocrânienne héréditaire" for this condition [3]. One of the most colourful families, descendants of a Chinese named "Arnold Head", was probably described by Jackson, he was able to trace 356 members of this family of whom 70 were affected with the "Arnold Head" [7]. CCD was originally thought to involve only bones of membranous origin, more recent and detailed clinical investigations have shown that CCD is a generalised skeletal dysplasia affecting not only the clavicles and the skull but the entire skeleton. CCD was therefore considered to be a dysplasia rather than a dysostosis [8].
Two-dimensional radiographs provide an overview of this condition but sometime may fail to accurately determine morphology of impacted teeth, there alignment, ectopic locations, proximity with vital structures like inferior alveolar canal and maxillary sinus and root formation etc because of inherent limitations like magnification, geometric distortion and superimposition of structures [4]. Three-dimensional images of CBCT gives more valuable accurate reconstruction of real anatomy than 2-dimensional radiographic images in such cases [9].

\section{CASE REPORT}

A 18- year old male patient reported to department of Oral Medicine and Radiology, Rishiraj College of Dental Sciences and Research Centre with chief complaint of missing teeth in both the arches. Medical history revealed recurrent pain in shoulders and dislocation by minor injuries. General physical examination revealed a thin build body and short stature. The shoulders were opposable over chest without pain or external force (Fig-1), A palpable groove was present in frontal bone in midline extending 
from forehead towards vertex,broad base ala of nose, with an interpupillary distance of $66 \mathrm{~mm}$.

Intraoral examination revealed multiple retained deciduous teeth, multiple missing teeth in maxillary and mandibular arches. On basis of clinical examination, the patient was provisionally diagnosed as having Cleidocranial dysplasia.

Radiological investigations included a panoramic radiograph, lateral cephalogram, posteroanterior view of the skull, chest and pelvis, hand-wrist radiograph, cone beam computed tomography of maxilla and mandible. Panoramic radiograph revealed multiple teeth like structures within maxilla and mandible suggestive of impacted supernumerary and permanent teeth (total number of teeth present, 36). The ascending rami of mandible appeared narrow with nearly parallel anterior and posterior borders. The coronoid processes was slender and pointed. Zygomatic arch was thin and downward tilt (Fig-2). Posteroanterior view of the skull (Fig-3) and Lateral cephalogram (Fig-4) shows dysmorphic skull features seen like increased circumference of head, open sutures, persistent anterior fontanelle, complete agenesis of frontal sinus, multiple wormian bones and thin cortical plates and absence of nasal bone. After completing all radiological and clinical investigations, the patient was confirmed as having cleidocranial dysplasia.

Chest radiograph revealed hypoplastic clavicles at acromial end (lateral) bilaterally with narrow thorax (Fig-5). Pelvic radiography showed angle between neck of femur and shaft (Neck Shaft Angle) $\mathrm{NSA}=130^{\circ}$ bilaterally (Fig-6). Hand -wrist radiograph (Fig-7) showed normal joint and articular surfaces, Fishman Skeletal Maturity Index (SMI) 11. Cone Beam Computed Tomography demonstrated all permanent teeth, retained deciduous teeth and supernumerary teeth. Total number of teeth present 38. Maxillary Permanent central incisor and lateral incisor are impacted and erupting palatal to the deciduous teeth, Maxillary central incisors are horizontally placed having close apices. Three supernumerary seen in maxillary anterior region and they are lying close to nasal cavity. Central incisors are malformed having deep lingual pit. Both central incisors are approximating with incisive canal. Right maxillary sinus show thickening of sinus lining. Malaligned mandibular anterior present. Multiple impacted teeth seen bilaterally in canine and premolar region. Malaligned mandibular premolar present bilaterally with root towards lingual cortical plate and crown submerged towards cortical plate. Crown of impacted mandibular right first premolar approximating with the tooth follicle of supernumerary crown. Crown of mandibular left first premolar is approximating with the impacted tooth follicle and mental foramen .Malaligned right first molar with crown submerged below cortical plate. Mandibular right first molar is showing dilacerated roots. Malpositioned and impacted mandibular second and third molar are present along the anterior border of ascending ramus of mandible. Both third molar tooth buds showing open apex.

Most of above findings are clearly appreciable on CBCT data not in the conventional panoramic radiograph.

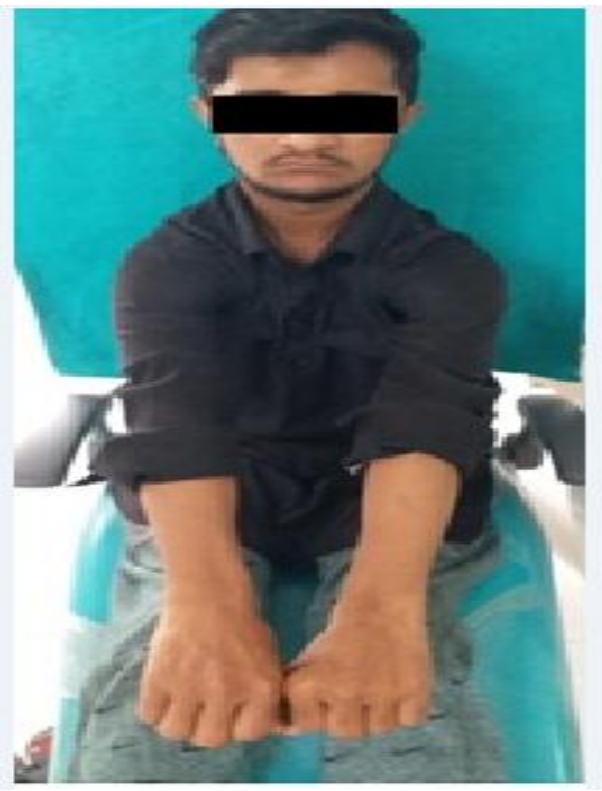

Fig-1: The patient, showing a groove present in frontal bone in midline and opposable shoulders over chest.

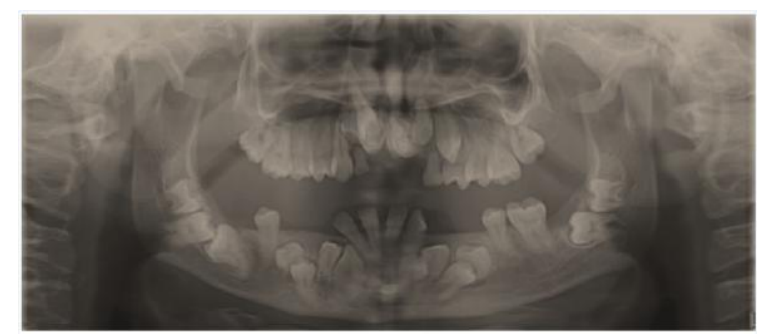

Fig-2: Panoramic radiograph showing multiple impacted permanent, supernumerary teeth, retained deciduous teeth and other features.

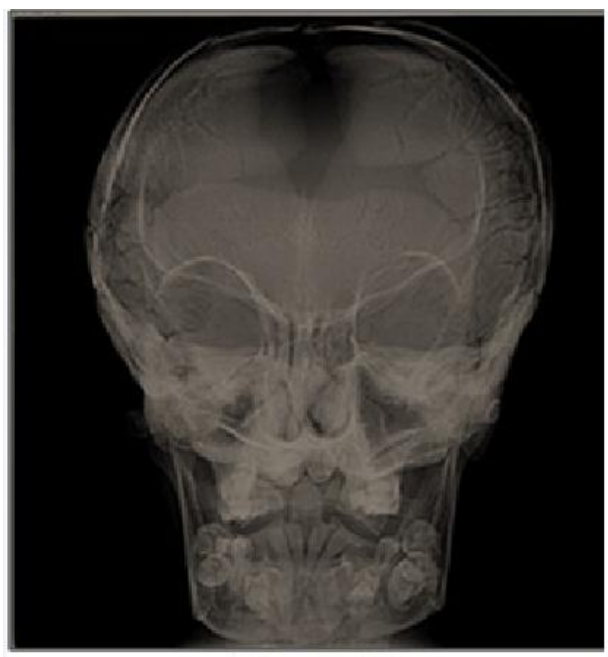

Fig-3: Postero-anterior view of the skull showing dysmorphic features of skull 


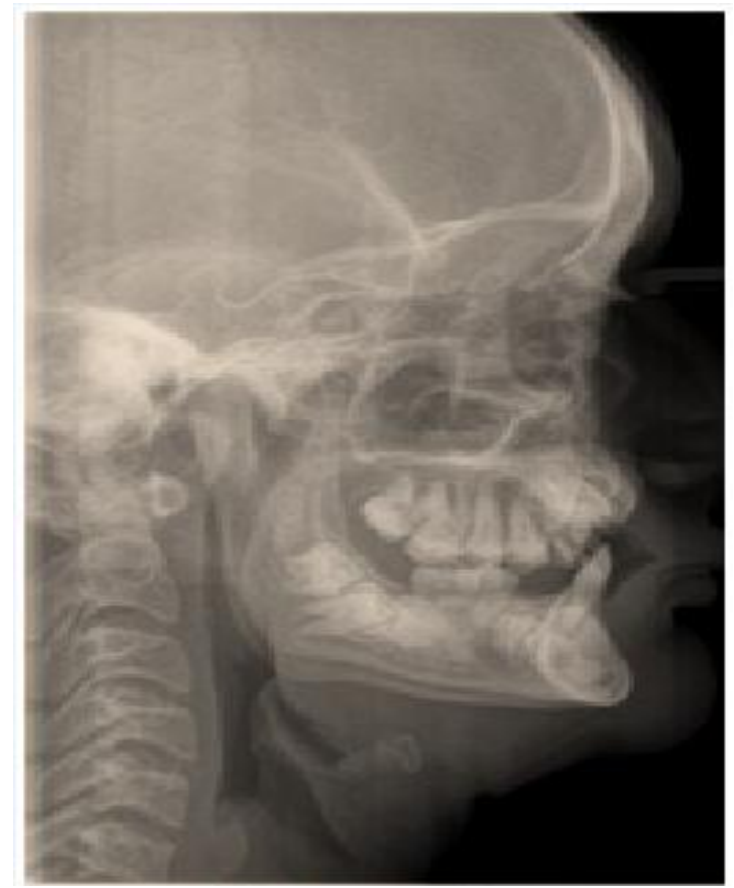

Fig-4: Lateral cephalogram showing complete absence of nasal bone.

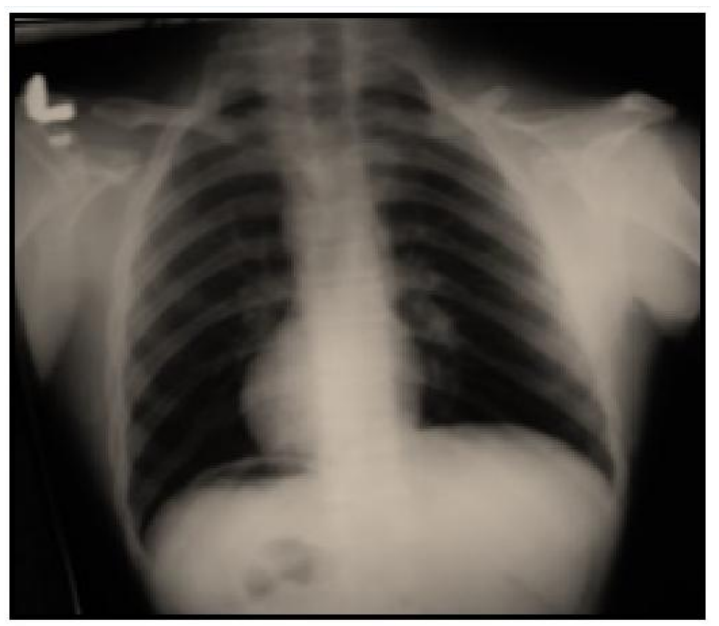

Fig-5: Chest x ray, showing Hypoplastic clavicles with narrow thorax

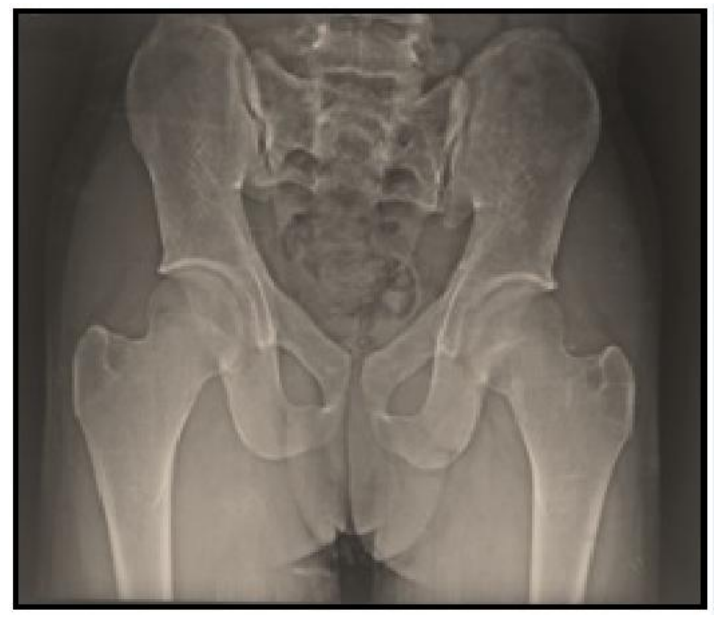

Fig-6: Antero-posterior view of pelvis showing angle between neck of femur and shaft (NSA) is $130^{\circ}$ bilaterally.

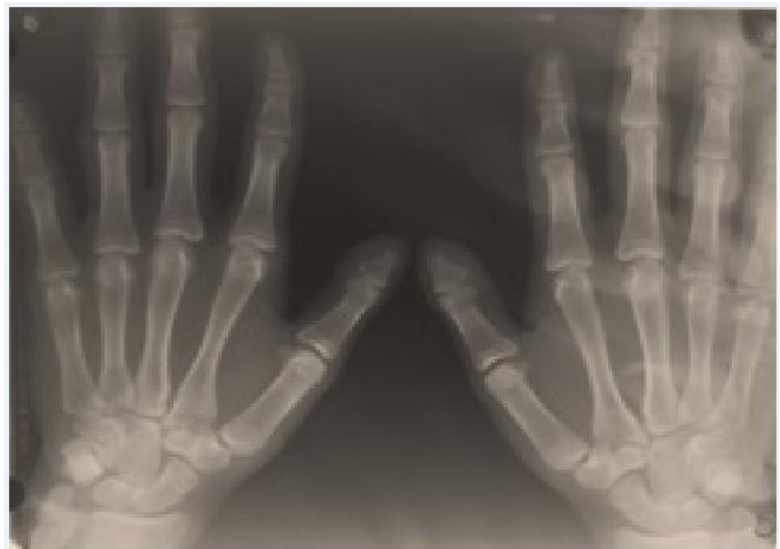

Fig-7: Hand -wrist radiograph showed normal joints and articular surfaces with SMI 11.

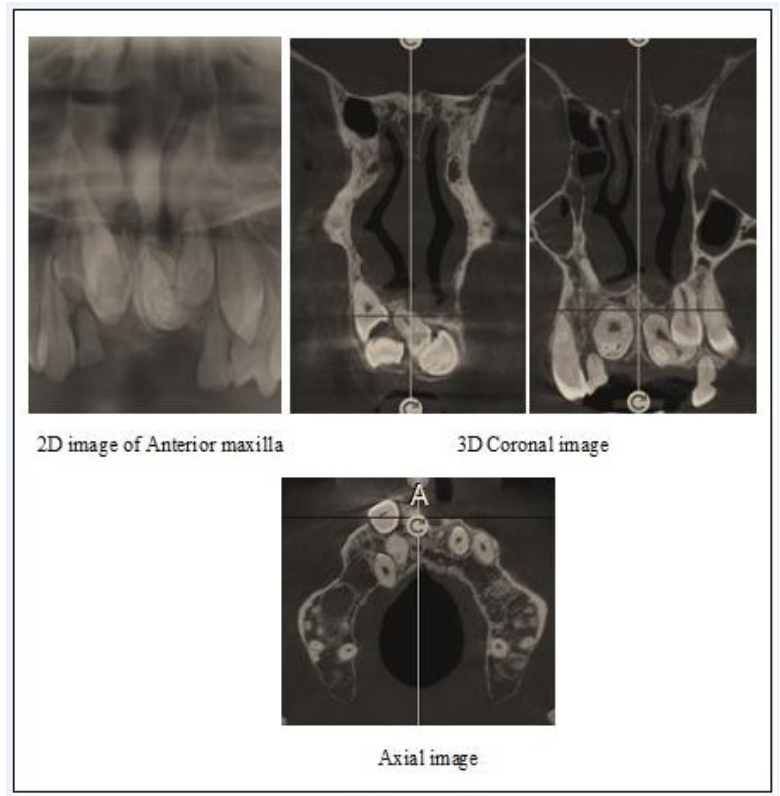

Fig-8

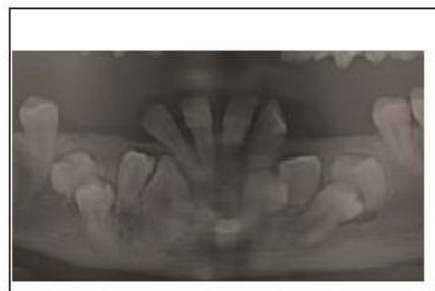

$2 \mathrm{D}$ image of anterior mandible and premolar region

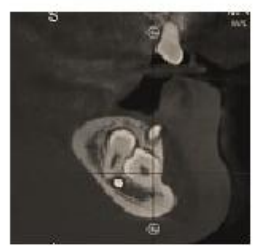

Sagittal image of 3334 region

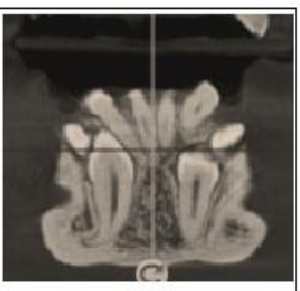

3D Coronal image

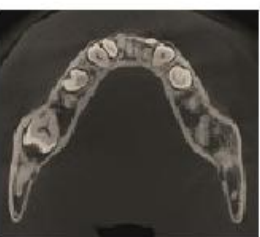

Arial image
Fig-9 
Comparison between conventional 2D image and 3D image of anterior maxilla and mandible. Coronal and sagittal images showing unambiguous morphology, location and alignment of impacted teeth.

\section{DISCUSSION}

We presented a case of CCD having typical features and the role of CBCT in its diagnosis and further treatment. Cleidocranial dysplasia is (CCD) an autosomal dominant condition. This is caused by mutation in CBFA1 gene [10]. This gene controls differentiation of osteoblasts from precursor cells. Recent findings suggest Cbfa1 is not only essential for osteoblast formation but a major regulator of chondrocyte differentiation. Therefore both intramembranous and endochondral bone formation is affected [1, 11, 12]. Typical clinical and radiological findings of CCD is given in Table-1.

Table-1

\begin{tabular}{|c|c|c|}
\hline Clinical Findings & Radiographic findings & $\begin{array}{l}\text { Seen in } \\
\text { present case }\end{array}$ \\
\hline \multicolumn{3}{|l|}{ Skull and Dentition } \\
\hline $\begin{array}{l}\text { Broad forehead with frontal } \\
\text { bossing }\end{array}$ & - & Yes \\
\hline Hypertelorism & - & No \\
\hline Mid-frontal groove & $\begin{array}{l}\text { Incomplete ossification of metopic suture and Failure of closure of anterior } \\
\text { fontanelle }\end{array}$ & Yes \\
\hline- & Wormian bones & Yes \\
\hline- & Aplasia or Hypoplasia of frontal and maxillary sinus & Yes \\
\hline Depressed Nasal Bridge & Aplasia Nasal bone & Yes \\
\hline High arched palate & - & No \\
\hline- & Underdevelopment of Zygomatic bone and processes & Yes \\
\hline- & Pseudomandibular prognathism & Yes \\
\hline- & Upward and posteriorly pointing coronoid processes & Yes \\
\hline- & Parallel borders of ascending ramus of mandible & Yes \\
\hline- & Delayed union of the mandibular symphysis & No \\
\hline- & Small cranial base with reduced sagittal diameter with a large foramen magnum & No \\
\hline $\begin{array}{l}\text { Partially edentulous Maxillary } \\
\text { and Mandibular arches }\end{array}$ & $\begin{array}{l}\text { Retained primary teeth, delayed eruption of permanent teeth and multiple } \\
\text { impacted supernumerary teeth }\end{array}$ & Yes \\
\hline Normal primary dentition & - & Yes \\
\hline- & Predominance of supernumerary teeth in anterior and premolar region of jaws & Yes \\
\hline- & $\begin{array}{l}\text { There morphology of supernumerary teeth appear similar to permanent teeth } \\
\text { making it difficult to differentiate }\end{array}$ & Yes \\
\hline \multicolumn{3}{|l|}{ Thorax } \\
\hline $\begin{array}{l}\text { Opposable shoulders over chest } \\
\text { without external force } \\
\text { Narrow sloping shoulders }\end{array}$ & $\begin{array}{l}\text { Hypoplasia of clavicles at acromial end } \\
\text { - }\end{array}$ & Yes \\
\hline- & Small bell shaped Thoracic cage with short oblique ribs & No \\
\hline \multicolumn{3}{|l|}{ Pelvis } \\
\hline- & Wide symphysis pubis with large femoral epiphysis & No \\
\hline- & Coxa vara & No \\
\hline \multicolumn{3}{|l|}{ Hand wrist } \\
\hline- & $\begin{array}{l}\text { Presence of both proximal and distal epiphyses in the second metacarpals and } \\
\text { metatarsals }\end{array}$ & No \\
\hline- & Poorly developed terminal phalanges giving tapered appearance to digit. & No \\
\hline $\begin{array}{l}\text { Hypoplastic or dysplastics nails } \\
\text { can be present }\end{array}$ & - & No \\
\hline \multicolumn{3}{|l|}{ Others } \\
\hline Short stature & - & Yes \\
\hline Hearing impairment & - & No \\
\hline
\end{tabular}

Table-1 showing typical clinical and radiological findings in patient with Cleidocranial Dysplasia.

Due to the inherent limitations of the conventional radiographs, CBCT investigations can be advised in lieu of panoramic and skull radiographs as more precise, accurate and perfect analysis of the jaws and skull can be done [4]. Three dimensional visualization of the structures gives the clinicians and specialists alike insight into the bony variations and assist them in proper treatment planning.
Conventional diagnostic images like panoramic radiograph in cases of multiple impacted teeth specially seen in anterior region in CCD may cause superimposition causing difficulty in interpretation, morphological assessment and location to designate tooth as permanent or supernumerary to plan preservation or extraction of teeth [4]. Three dimensional view for assessing alignment of teeth along with its relationship to vital structure like maxillary sinus and inferior alveolar canal is valuable for surgical approach when indicated. Even root morphology like dilaceration and root completion required before 
orthodontic extrusion procedure can be accurately assessed if prior CBCT is done. Maxillary arch is having a complex anatomy due to the presence of multiple small and large bones like nasal bone, zygomatic bone, orbital bone, maxillary sinuses etc. With such complex anatomy conventional radiological tools can be misleading in cases like CCD where the clinicians has to determine the prognosis and treatment of the impacted teeth [9].

Multiple impacted teeth in CCD can be associated with follicular pathologies like dentigerous cyst which may have been missed in conventional radiograph as they cannot depict the most accurate extension of the pericoronal radiolucency [13, 14]. On CBCT images follicles of impacted teeth can be evaluated accurately for early detection of pathologies.

As CCD may require multiple extraction and to justify patients chief complaint of missing teeth CBCT may further act as guide for implant planning and rehabilitation. Quantitative assessment of the bone can be done on CBCT by virtual planning. Subjective qualitative assessment of the bone is also possible with use of CBCT and by assessing the cortical and cancellous bone.

\section{CONCLUSION}

We presented this case to demonstrate the usefulness of CBCT in CCD, as it gives a detailed three dimensional information about the structures in jaw including impacted teeth which are most common finding in CCD. Imaging these teeth accurately may not be possible on $2 \mathrm{D}$ radiograph because of its limitations but it is possible on CBCT. Thus for diagnosis and treatment planning of similar conditions with multiple impacted and supernumerary teeth we recommend the use of CBCT.

\section{Conflict of interest: None.}

Sources of any support in any form (grants, equipments, material or drugs): None

\section{REFERENCES}

1. Mundlos S. Cleidocranial dysplasia: clinical and molecular genetics. Journal of medical genetics. 1999 Mar 1;36(3):177-82-182.

2. Scheuthauer G. Kombination rudimentärer Schlüsselbeine mit Anomalien des Schädels beim erwachsenen Menschen. Allg Wien Med Ztg.1871;16:293-295.

3. Marie P, Sainton P. Sur la dysostose cléidocranienne héréditaire. Rev Neurol. 1898;6:835838.

4. Gupta N, Gogri A, Kajale M, Kadam S. Cone beam computed tomography: An inevitable investigation in cleidocranial dysplasia. Contemp clin Dent. 2015 Apr-June; 6(2): 257-261.
5. Mohan RP, Suma GN, Vashishth S, Goel S. Cleidocranial dysplasia: clinico-radiological illustration of a rare case. Journal of oral science. 2010;52(1):161-166.

6. Golan I, Baumert U, Hrala BP, Mussig D. Dentomaxillofacial variability of cleidocranial dysplasia: clinicoradiological presentation and systematic review. Dentomaxillofacial radiology. 2003 Nov;32(6):347-54.

7. Jackson WP. Osteo- dental dysplasia (Cleidocranial dysostosis).: The» Arnold Head». Acta Medica Scandinavica. 1951 Jan 12;139(4):292307.

8. Rimoin DL. International nomenclature of constitutional diseases of bone. The Journal of pediatrics. 1978 Oct 1;93(4):614-618.

9. Dalessandri D, Laffranchi L, Tonni I, Zotti F, Piancino MG, Paganelli C, Bracco P. Advantages of cone beam computed tomography (CBCT) in the orthodontic treatment planning of cleidocranial dysplasia patients: a case report. Head \& face medicine. 2011 Dec;7(1):6-15.

10. Mundlos S, Mulliken JB, Abramsom DL, Warman ML, Knoll JH, Olsen BR. Genetic mapping of cleidocranial dysplasia and evidence of a microdeletion in one family. Human molecular genetics. 1995 Jan 1;4(1):71-75.

11. Mundlos S, Otto F, Mundlos C, Mulliken JB, Aylsworth AS, Albright S, Lindhout D, Cole WG, Henn W, Knoll JH, Owen MJ. Mutations involving the transcription factor CBFA1 cause cleidocranial dysplasia. Cell. 1997 May 30;89(5):773-779.

12. Li Y, Pan W, Xu W, He N, Chen X, Liu H, Darryl Quarles L, Zhou H, Xiao Z. RUNX2 mutations in Chinese patients with cleidocranial dysplasia. Mutagenesis. 2009 Jun 10;24(5):425-431.

13. McNamara CM, O'Riordan BC, Blake M, Sandy JR. Cleidocranial dysplasia: radiological appearances on dental panoramic radiography. Dentomaxillofacial Radiology. 1999 Mar 1;28(2):89-97.

14. Roberts T, Stephen L, Beighton P. Cleidocranial dysplasia: a review of the dental, historical, and practical implications with an overview of the South African experience. Oral surgery, oral medicine, oral pathology and oral radiology. 2013 Jan 1;115(1):46-55.

15. Ramos RM, Rodríguez MC, Fano V. Clinical, radiological, and auxological characteristics of patients with cleidocranial dysplasia followed in a pediatric referral hospital in Argentina. Archivos argentinos de pediatria. 2018 Aug;116(4):e560566.

16. Tanaka JL, Ono E, Médici Filho E, Castilho JC, Moraes LC, Moraes ME. Cleidocranial dysplasia: importance of radiographic images in diagnosis of the condition. Journal of oral science. 2006;48(3):161-166. 